\title{
Detecting Punctual Damage to Gears through the Continuous Morlet Wavelet Transform
}

\author{
Andre Luis Vinagre Pereira, ${ }^{1}$ Aparecido Carlos Gonçalves $\mathbb{D}^{2},{ }^{2}$ Rubens Ribeiro, ${ }^{1}$ \\ Fábio Roberto Chavarette ${ }_{\left(\mathbb{D},{ }^{3} \text { and Roberto Outa }\right.}^{4}$ \\ ${ }^{1} P P G$ in Mechanical Engineering, DEM, FEIS/UNESP, Ilha Solteira, Brazil \\ ${ }^{2}$ Department of Mechanical Engineering, DEM, FEIS/UNESP, Ilha Solteira, Brazil \\ ${ }^{3}$ Department of Mathematics, MAT, FEIS/UNESP, Ilha Solteira, Brazil \\ ${ }^{4}$ Department of Biofuels, Araçatuba Technology College, FATEC, Sorocaba, Brazil \\ Correspondence should be addressed to Aparecido Carlos Gonçalves; aparecido.carlos@unesp.br
}

Received 26 May 2020; Revised 20 August 2020; Accepted 3 September 2020; Published 15 September 2020

Academic Editor: Marco Cocconcelli

Copyright (c) 2020 Andre Luis Vinagre Pereira et al. This is an open access article distributed under the Creative Commons Attribution License, which permits unrestricted use, distribution, and reproduction in any medium, provided the original work is properly cited.

\begin{abstract}
In predictive maintenance, vibration signal analyses are frequently used to diagnose reducer failures because these analyses contain information about the conditions of the mechanical components. Reducer vibration signals are very noisy and the signalto-noise ratio is so low that extracting information from the signal components is complex, especially in practical situations. Therefore, signal processing techniques are used to solve this problem and facilitate the retrieval of information. In this work, the adopted technique included noise-canceling technique, synchronous temporal mean (TSA), and continuous Morlet wavelet transform (CWT), designed to extract resources and diagnose local gear damage. These techniques are used in measured signals in an experimental workbench consisting of the gear pair coupled to a motor and a generator. The experiment was monitored according to the conditions of a gear pair throughout its useful life. The continuous wavelet transforms accurately identified faults in the gear teeth, and it was possible to detect in which tooth the fault was occurring.
\end{abstract}

\section{Introduction}

The purpose of maintenance is to identify, diagnose, predict, prevent, and eliminate damage and, consequently, maintain a mechanical system in ideal working condition. Modern maintenance is not only about eliminating failures but also about detecting a potential hazard of an impending fault in system operation. Therefore, the diagnosis serves to adjust the condition of the system and identify the location, type, and reason for a developing hazard.

Reducers have several industrial applications; therefore, it is extremely important to identify any signs of component failure in the initial stages. Faults in components are often detected using vibration signals. However, the data can be complex, even when obtained in real applications, because they include noise from other sources. Thus, any useful information is diffused, making it difficult to view a specific system factor and reach a conclusion.
For this reason, techniques for diagnosing the conditions of reducer gearboxes are used to improve the operability and availability of equipment. In this paper, gear faults were diagnosed using vibration analysis with continuous wavelet transform.

This tool was selected because it can detect punctual damage. The result is compared with an experiment whereby the conditions of a gear pair are monitored until the gear reaches the end of its useful life.

\section{Theoretical Framework}

All current gear diagnostic techniques have a common goal, which is to check and locate the smallest fault as soon as possible. Therefore, any fault that compromises gear performance, manifested in the vibration signal, can be detected using the available techniques. Due to noise interference, the information is usually hidden in the vibration signal. Thus, 
the focus lies in discovering which technique is sensitive enough to find the fault concealed in the noise.

2.1. Vibration Analysis. McFadden and Toozhy [1] and Bonnardot et al. [2] affirm that time-synchronous averaging (TSA) on a vibration signal is the most successful technique for processing vibration signals and diagnosing faults in rotating machines.

The technique was initially proposed in 1986 by McFadden [3] and later by Dalpiaz et al. [4] who implemented McFadden's idea and used phase modulation kurtosis as an indicator of the presence of cracks. Lin et al [5] investigated the effect of a gear tooth crack and correlated it with a vibration signal of the reducer.

Silva [6] addressed the severity of such a fault when diagnosing and monitoring speed reducers subjected to power variation. The author examined the potentialities employed for this problem with thirteen commonly used monitoring techniques. Three of these techniques were in the time domain, namely, time-synchronous average, residual signal, and demodulation. Five techniques were in the amplitude domain, namely, variance, RMS, skewness, kurtosis, and crest factor. One technique was in the frequency domain, namely, the amplitude spectrum. Lastly, four techniques were in the time-frequency domain, namely, short-time Fourier transform, wavelet, the Wigner-Ville distribution, and the pseudo-Wigner-Ville distribution. Thus, the author concluded that through the simulated signals, all thirteen techniques are susceptible to power variations and are, therefore, unsuitable for solving the problem. In this case, the author proposes three analysis procedures based on the fourth statistical moment concerning the origin of the probability density function of beta distribution: (i) global historical analysis; (ii) historical individual analysis; and (iii) independent individual analysis. He submitted the three procedures to experimental trials with unambiguous variations of torque or velocity and for two defect conditions: (a) without mesh and (b) with a broken tooth. The experiments revealed that the three procedures strongly signal the presence of the broken tooth and, in addition, both (ii) and (iii) are able to indicate precisely which tooth is broken.

Green [7] studied the integration of vibration analysis and lubricant oil analysis techniques to objectify the fault modes associated with the gears of a speed reducer.

Gonçalves et al. [8] say that among the techniques used for predictive maintenance of reducers, the most used are the oil and vibration analyses since the use of these two techniques together provides better measurements about the health condition of mechanical equipment during its working period.

Gonçalves and Padovese [9] studied vibration and lubricant analysis together to check the conditions of a lubricant. They concluded that although the limits of control for each parameter need to be adjusted depending on the type of lubricant and equipment, variations in the viscosity of $\pm 10 \%$, TAN greater than $3 \mathrm{mg} / \mathrm{g}$, and water exceeding 100 to $500 \mathrm{ppm}$ are usually sufficient for intervention or at least for further investigation if a vibration analysis is also performed.

Almeida and Padovese [10] investigated the relationship between vibration (mechanical signature) and lubrication of rotating machines and thus, as the starting point of this study, sought to evaluate the effect of viscosity variations of the lubricant on the vibration signal of gearboxes. The work presented a large experimental database, discussed several methods of signal processing, and revealed a characteristic of the vibration signal that was able to identify changes in the viscosity of lubricating oil in the case presented.

Recent advances in signal processing in the time and frequency domains have provided very powerful and interesting tools for signal analysis. Continuous wavelet transform is a time-frequency signal analysis method that has been improved and widely used recently. Moreover, it has the characteristic of the time domain and the advantages of the frequency domain.

Wang et al. [11] used both discrete and continuous wavelet transforms to detect abnormal transients generated by early gear damage.

2.2. Predictive Maintenance. Mobley [12] reported that predictive maintenance is performed on machines before a fault would occur if traditional maintenance were not performed. Rotating machines usually show signs of impending faults before breakage occurs. Signs include increased temperature or surface cracks, increased vibration level, change in vibration patterns in the frequency spectrum, and changes in time waveforms. Subsequently, these data are analyzed to identify when a fault will occur and maintenance is scheduled before that time.

Zeng et al. [13] state that for good maintenance, it is important to know the bathtub curve for machine wear and its three periods. Many useful life distributions have the format of a bathtub curve and many real-life data exhibit this property.

The bathtub curve has three periods: the infant mortality period, the constant or normal period, and the wear-out period after the end of the useful life.

Roesch [14] points out that the early infant mortality period is when relatively early failures occur at the start of equipment operation, characterized by high severity with a gradual decline. This phenomenon is caused by the softening of equipment parts.

Arato [15] affirms that once the softening has stopped, the severity of the investigated parameter stabilizes at a low and constant level for a long period until the end of its useful life.

Zeng et al [13] point out that after the useful life of the equipment, the wear-out period begins, which is when the equipment fails due to wear and tear, and the severity of the investigated parameter increases over time.

In predictive maintenance, the equipment is monitored until the fault is diagnosed and the end of the bathtub curve is divided into zones.

Figure 1 indicates the behavior of equipment from the start point of a fault to the point at which the fault occurs. 


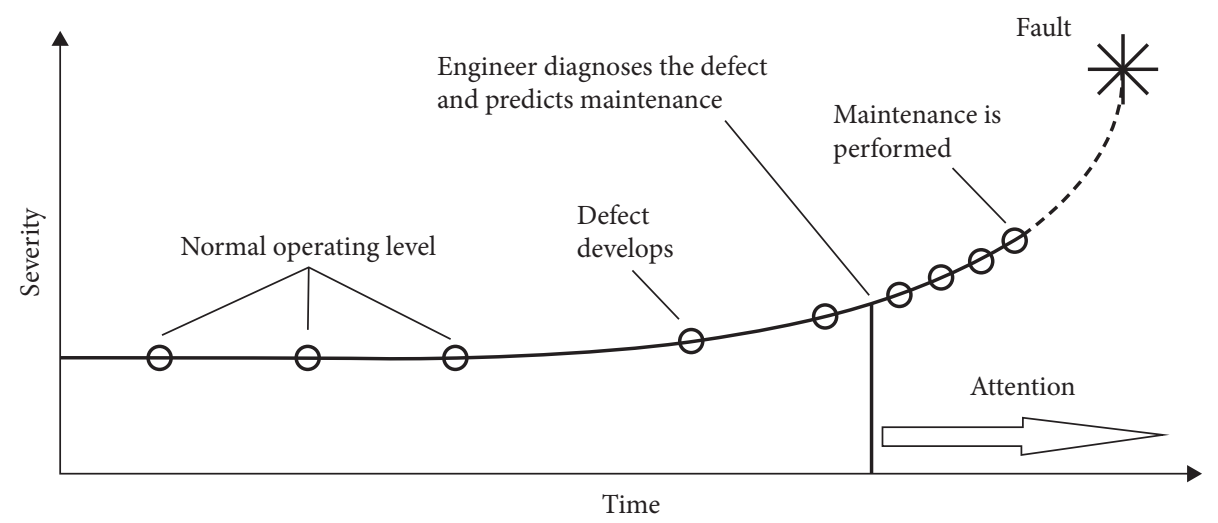

FIGURE 1: Stages of predictive maintenance (source: adapted from [15]).

After the point of defect development and after the engineer has diagnosed the fault, the process enters an attention period in which the frequency of analyses and maintenance increases. Vibration analysis provides early warning indications and helps detect these fault mechanisms before reaching an alarming level.

\subsection{Condition Monitoring Using Vibration Analysis.} Rotating machines emit vibrations and, consequently, noise. The characteristics of each machine have a vibration signature. Therefore, a change in the vibration signature caused by a change in the machine state can help detect defects at the very beginning, before they become critical. This is the objective of condition monitoring, where information obtained from a machine signature is used to detect faults at an early stage. In general, basic condition monitoring is subdivided into three main steps. Firstly, a relevant physical quantity is measured, after which the collected data are processed and the machine state characteristics are extracted and, lastly, the extracted machine state resources are compared to the reference values.

2.4. Signal Processing. Several signal processing techniques are applied to stationary signals both in the frequency domain and time domain. However, a more recent trend has been the representation in time-frequency analysis, such as the wavelet transform.

2.5. Wavelet Transform. Spectral analysis or fast Fourier transform (FFT) is extremely useful for stationary signals with properties that change over time. However, Fourier analysis in the transform to the frequency domain loses information in the time domain.

To solve these problems, the wavelet transform was developed in the 1980s. This technique is efficient for the local analysis of nonstationary and fast signals. The wavelet transform is a mapping of a signal that is both local in time and frequency.

Wavelet analysis can be used to scale the window according to the desired frequency reading. Because the size of these windows is inversely related to the frequencies, a smaller window implies reading a high frequency and vice versa.

The base function for the wavelet transform is given in terms of the translation parameter, $b$, and the scale parameter, $a$, with the following mother wavelet:

$$
\psi_{a, b}(t)=\frac{1}{\sqrt{a}} \psi\left(\frac{t-b}{a}\right) .
$$

The wavelet transform, $W(a, b)$, of a time signal $x(t)$ is defined as an integral of the convolution of $x(t)$ with scaled and translated versions of the $\psi(t)$ mother wavelet function:

$$
W(a, b)=\frac{1}{\sqrt{a}} \cdot \int_{-\infty}^{+\infty} x(t) * \psi\left(\frac{t-b}{a}\right) \cdot \mathrm{d} t .
$$

When the $x(t)$ signal is periodic, the equation becomes a circular convolution, and the continuous wavelet transform is better calculated in the frequency domain, taking the following alternative form:

$$
W(a, b)=\sqrt{a} \cdot F^{-1} \cdot[X(f) * \Psi(a f)],
$$

where $X(f)$ and $\psi(f)$ are the Fourier transforms of the $x(t)$ signal and the wavelet with altered scale $\psi(t)$, respectively, and the $F^{-1}$ operator indicates the inverse Fourier transform.

The following equations indicate that wavelet analysis is a time-frequency analysis, and there is a universal reconstruction equation for any type of wavelet:

$$
x(t)=C_{\psi}^{-1} \iint W(a, b) \psi_{a, b}(t) \frac{\mathrm{d} a}{a^{2}} \mathrm{~d} b,
$$

where

$$
\begin{aligned}
C_{\psi} & =\int_{-\infty}^{+\infty} \frac{|\Psi(f)|^{2}}{|f|} \mathrm{d} f<\infty, \\
\Psi(f) & =\int \psi(t) \exp (-2 \pi i f t) \mathrm{d} t .
\end{aligned}
$$

The Morlet wavelet is derived from a Gaussian function, so these wavelets have a Gaussian window in the frequency domain. In the time domain, the Morlet wavelet can be written as 


$$
\psi(t)=\frac{1}{\sqrt{\pi f_{b}}} e^{j 2 \pi f_{c} t} e^{\left(-t^{2} / f_{b}\right)}
$$

where $f_{b}$ is a parameter related to bandwidth (variance) and controls the time-frequency resolution of the Morlet wavelet and $f_{c}$ is the central frequency. When applying the Fourier transform, the following equation is derived:

$$
\Psi(f)=\Psi^{*}(f)=e^{-\pi^{2} f_{b}\left(f-f_{c}\right)^{2}} .
$$

2.6. Time-Synchronous Average. Silva [16] points out that the synchronous time average (TSA) technique is widely used to detect gear faults, and it is useful for filtering asynchronous noises in vibration signals.

TSA uses the information of each revolution collected by a tachometer. Thus, it is possible to separate the vibration signal by revolution. Once the signal referring to each rotation of the machine is known, TSA groups the data that are exactly in the same angular positions. Finally, an average is calculated of all the data from the same angular position, resulting in the signal referring to the rotation without the asynchronous noises, namely, a time-synchronous average, as shown in Figure 2.

The longer the duration of measurement over many revolutions of the gear, the better the quality of the TSA. It reduces the asynchronous components of the vibration and average noise to zero because the expected value of the measurement in which the number of average revolutions is too large approaches zero.

\section{Experimental Materials and Methods}

The experiment was performed using a constructed experimental workbench, as shown in the schematic diagram in Figure 3, the photograph in Figure 4, and the specifications of its components in Table 1.

The workbench consists of the frequency inverter that controls the rotation of the three-phase electric motor with a maximum power of $3700 \mathrm{~W}$. This motor is connected to the reducer/multiplier using elastic grid couplings, with the gear pair 2.16 ratio in the form of a multiplier.

The multiplier output has a $4 \mathrm{kVA}$ electric generator attached that operates in its nominal rotation of $1800 \mathrm{rpm}$ and supplies a panel of lamps, totaling $1600 \mathrm{~W}$.

The accelerometer was mounted with the axis of sensitivity in the radial direction ("radial" accelerometer). Besides, the revolutions of the crown wheel axis were measured using a trigger and its signal was collected from the accelerometer, thus allowing the vibration signal to be related to each tooth of the gear.

In order not to have problems with statistical errors, the signal acquisition was made for a long period (120 seconds for gear at $14 \mathrm{~Hz}$ ) so that the signal of each turn contained a very high number of samples. TSA was used on a very long signal and the result was a signal equivalent to a noise-free gear turn. Also, to check for possible errors, each reading was repeated and the result was compared.

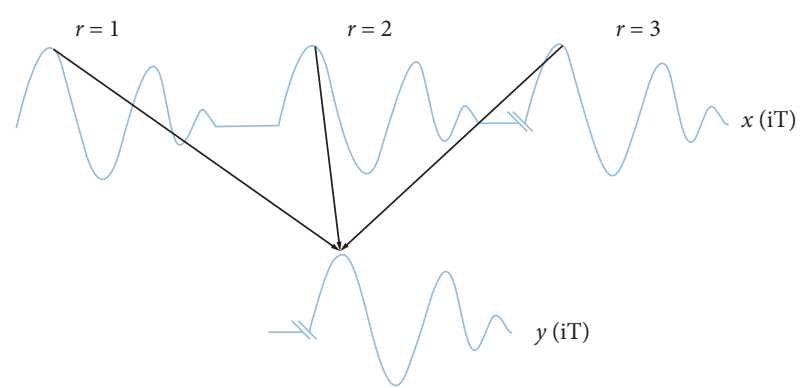

FIgURE 2: Layout for obtaining a time-synchronous average (source: [6]).

The gears were designed with straight teeth, module 1 , 1045 steal, and Brinell hardness of $220 \mathrm{HB}$. The crown had 95 teeth and the pinion had 44 teeth, so the multiplication factor was 2.16, as shown in Figure 5.

The project was designed with a width of $11 \mathrm{~mm}$ and a useful lifespan of 1 month or 720 hours, resulting in $3.60 \times 10^{7}$ cycles for the crown and $7.77 \times 10^{7}$ cycles for the pinion.

3.1. Signal Processing. The signals were processed using a program created with Octave software, for which the data were formatted and the signals were separated from the trigger and accelerometers into vectors so the starting point of each rotation could be seen. This information was used to calculate the TSA. This choice was based on other works where TSA proved to be a good method of filtering for asynchronous signals.

Once the noise was removed and the average rotation signal was obtained, the wavelet analysis was initiated. The mother wavelet used in this work is the Morlet wavelet, and to investigate the sensitivity of the method, the continuous wavelet transform was adopted to the radial vibration signal of this experiment. The changes in the vibration signal due to the vibration of the damaged teeth increased the magnitude in the wavelet analysis, thus revealing the location of the fault.

Throughout the experiment, the gear was rigorously inspected to locate possible damage to the teeth.

\section{Results}

The signals were divided into three periods according to the bathtub curve: the first infant mortality period, with high magnitudes distributed throughout all the gear teeth; the second constant or normal operation period lasts until the end of the useful life, with low magnitude characteristics; and lastly, the wear-out period starts at the end of the useful life.

4.1. Infant Mortality Period. Figure 6 shows the frequency maps of the first vibration signals collected from the bench at 1 hour and 8 hours of experiment, respectively. The figure shows a high magnitude throughout the gear, referring to the start of the useful life of the gear and the softening of the 


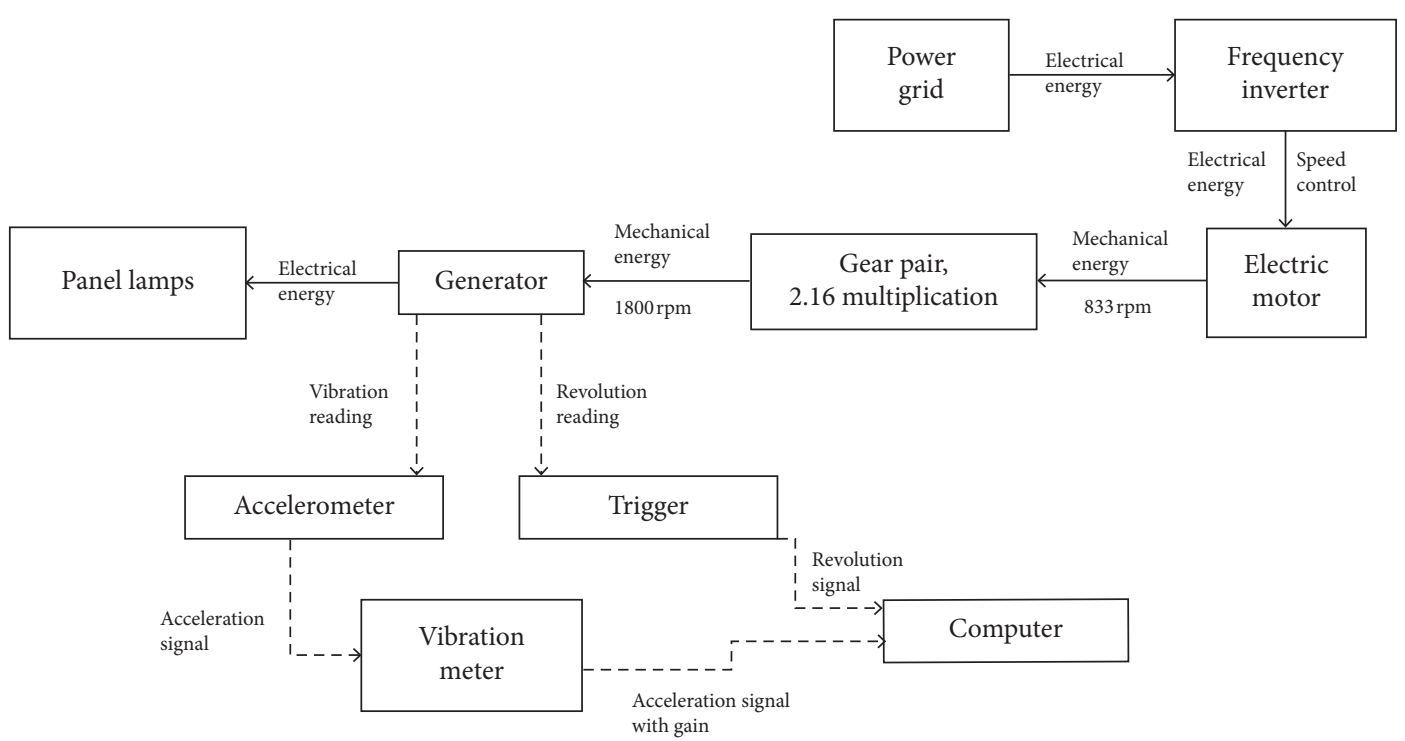

FIgURE 3: Schematic diagram of the workbench.

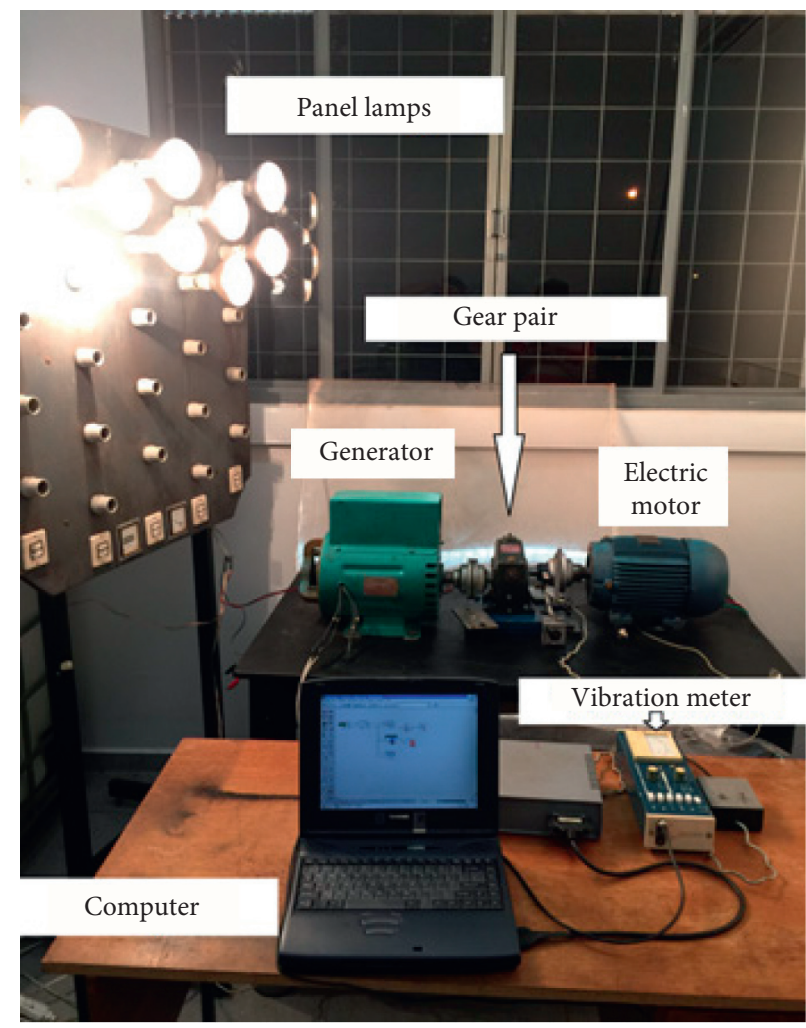

FIGURE 4: Workbench with its components.

teeth. It is also noted that the peaks are in the mesh frequency of the analyzed set, at $1300 \mathrm{~Hz}$.

During the infant mortality period of the gear, the signal magnitude decreased gradually. In this period, peaks were distributed throughout gear rotation. Figure 7 shows this gradual reduction, at 50 and 100 hours of the experiment.
Due to the low magnitude of the signal, the softening ended and the constant or useful life period began.

4.2. Constant or Normal Operation Period. The constant or normal operating period lasts until the gear reaches the end of its useful life and critical wear starts to occur. In this 
TABLE 1: Specification of the workbench components.

\begin{tabular}{lcc}
\hline Component & Manufacturer & Model \\
\hline Inertia table & - & - \\
Frequency inverter & Weg & CFW-08 \\
Electric motor & Weg & $100 \mathrm{~L}$ \\
Coupling & Falk & $4 \mathrm{~F}$ \\
Gearbox & Cestari & HS 0.44 \\
Generator & Kohlbach & $4 \mathrm{kVA}$ \\
Vibration meter & Robotron & 00042 \\
Accelerometer & MMF & KS 50 \\
Trigger & Sensor Balluff & BOS-15K \\
Microcomputer & Toshiba & Satellite 2180 \\
Acquisition software & IOTechInc & DASYLab 4.01.11 \\
\hline
\end{tabular}

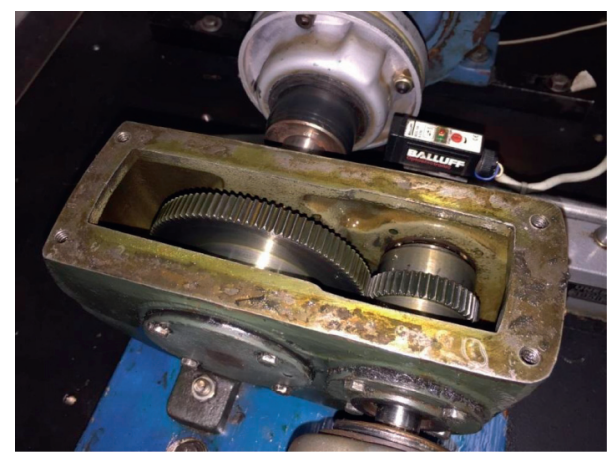

Figure 5: Gear pair.

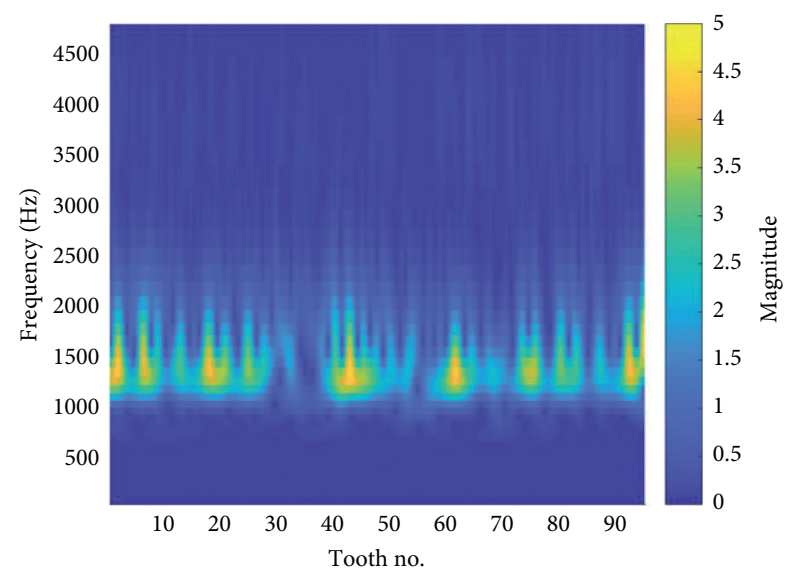

(a)

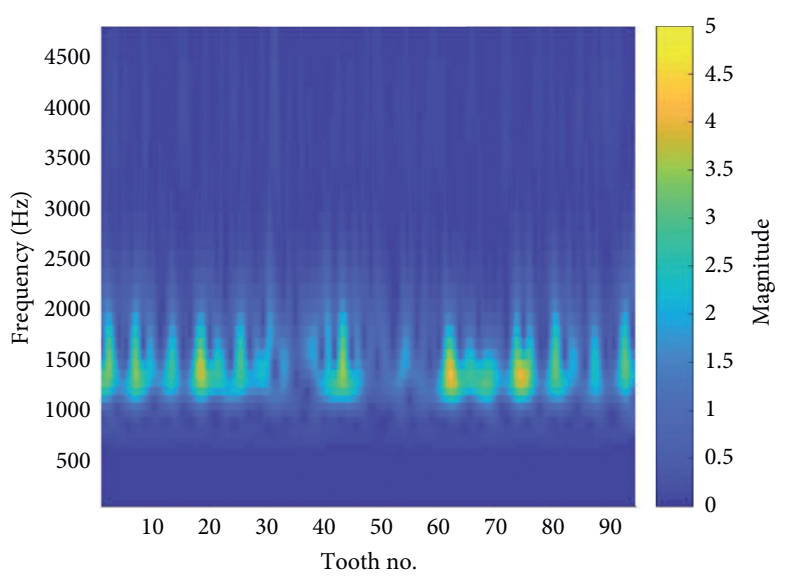

(b)

Figure 6: Wavelet analysis: (a) 1 hour and (b) 8 hours of experiment.

period, the signal has a low magnitude and remains stable for several hours. Figures 8 and 9 show the wavelet analysis and the magnitude scale that was altered for easier visualization.

The gear pair is designed for a lifespan of 720 hours. Once the useful lifespan is completed, catastrophic faults may occur, initiating the wear-out period or the end of the useful life.
Due to the size of the images in the figures, the peaks look the same and of the same intensity, but these are slightly less intense. The peaks in the signal have different characteristics and are distributed throughout the signal.

4.3. End of Useful Life. In this period, the gear is prone to catastrophic faults and greater attention should be given to 


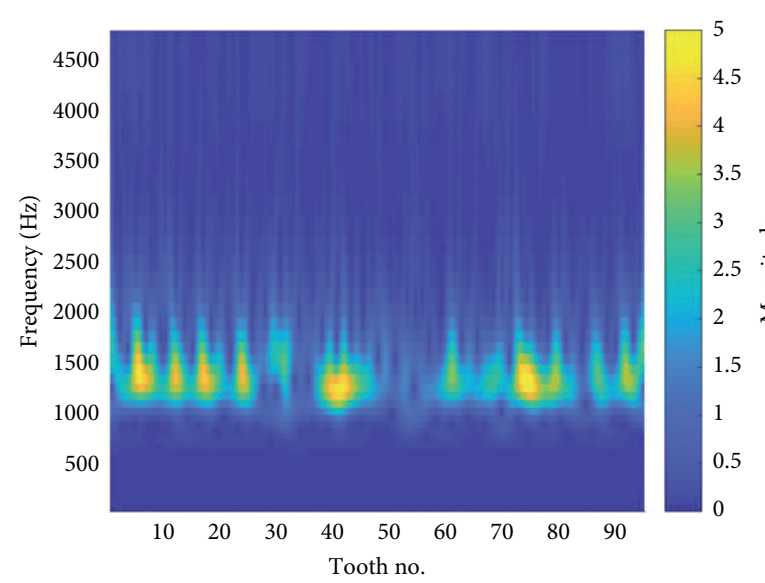

(a)

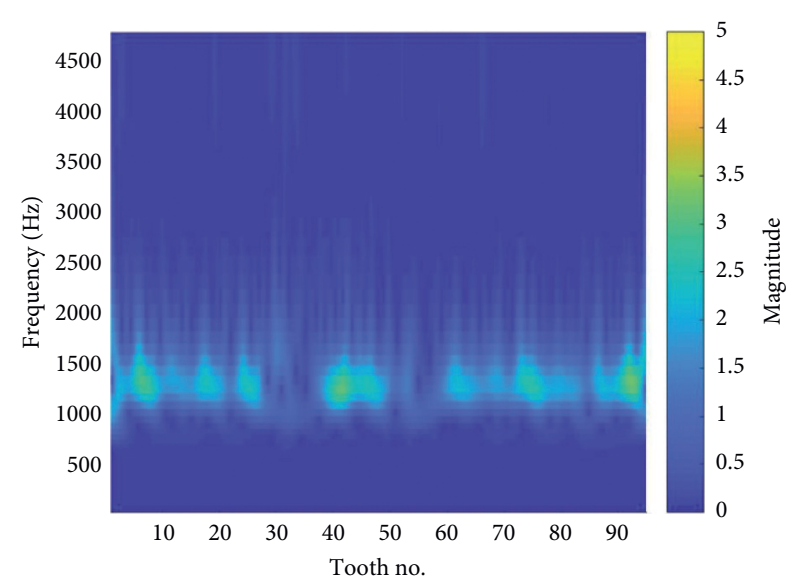

(b)

FIgURE 7: Wavelet analysis: (a) 50 hours and (b) 100 hours of experiment.

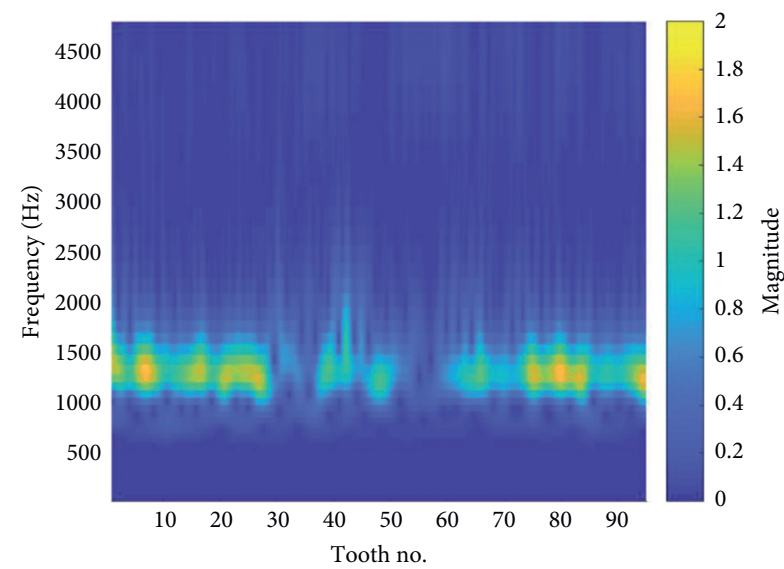

(a)

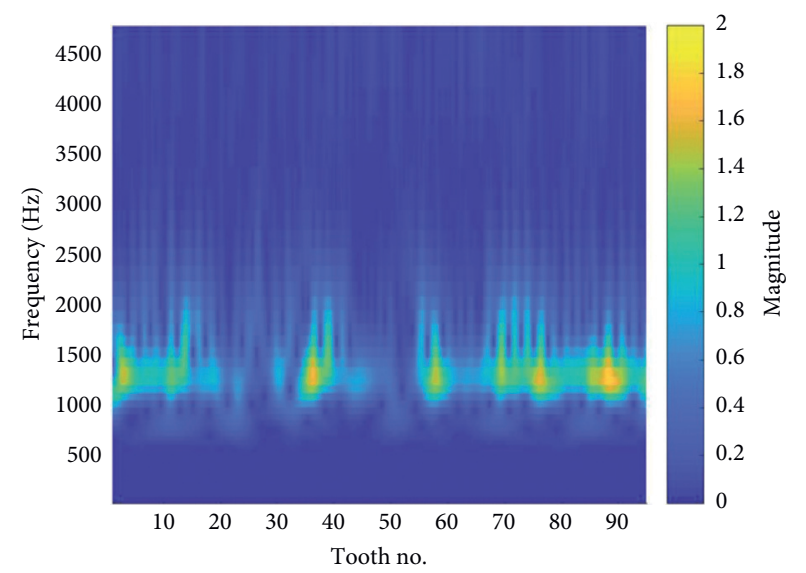

(b)

Figure 8: Wavelet analysis: (a) 300 hours and (b) 400 hours of experiment.

vibration analysis. Figure 10, for 700 and 800 hours,

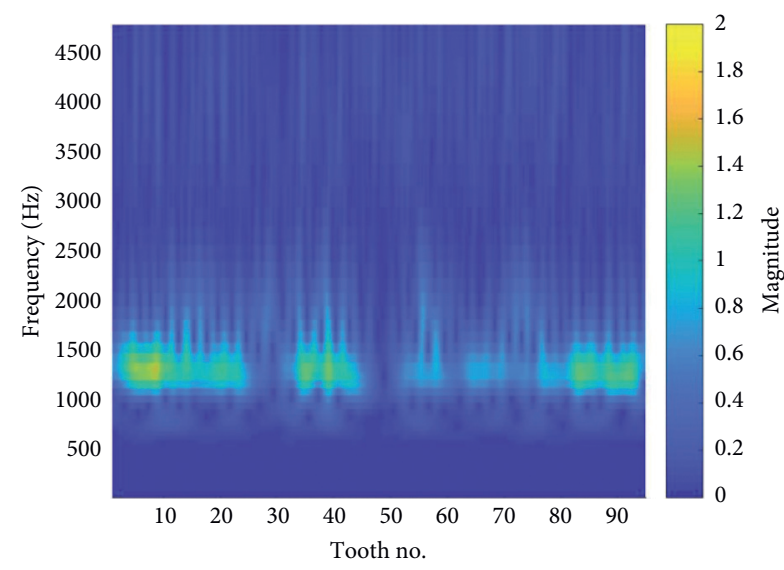

(a) respectively, referring to the end of the useful life of the gear

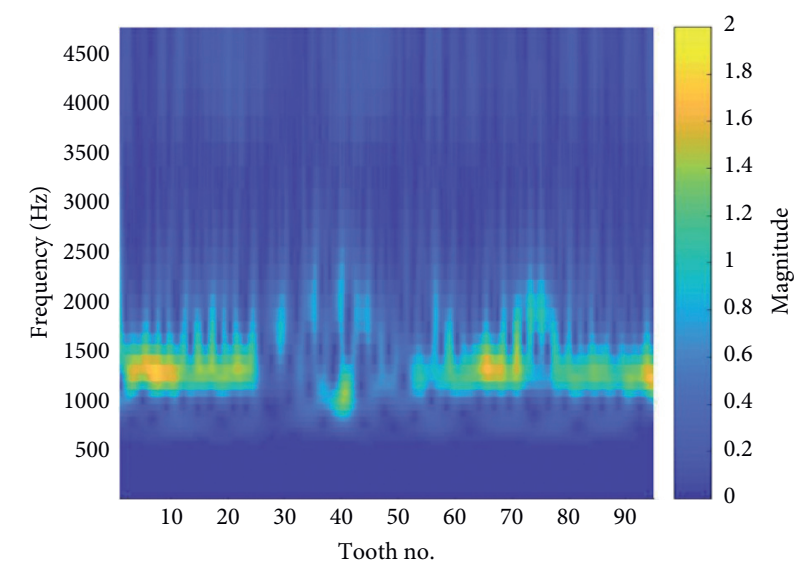

(b)

Figure 9: Wavelet analysis: (a) 500 hours and (b) 600 hours of experiment. 


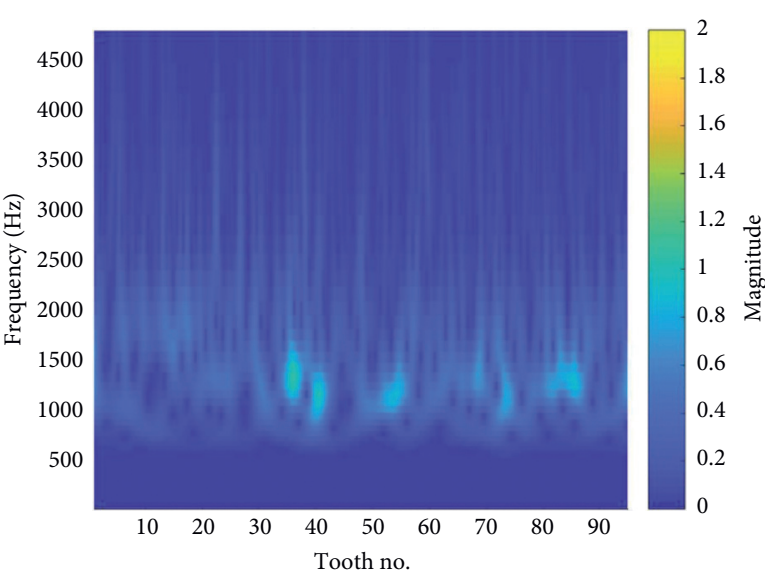

(a)

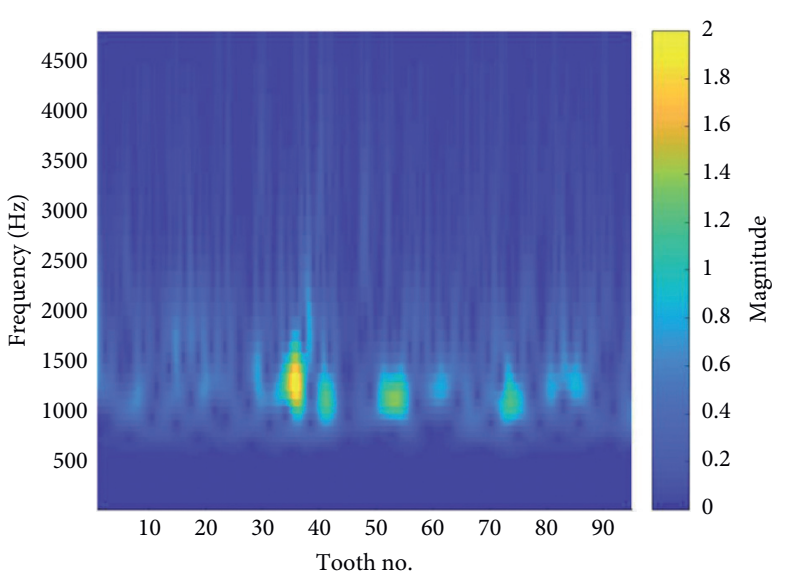

(b)

FIgURE 10: Wavelet analysis: (a) 700 hours and (b) 800 hours of experiment.

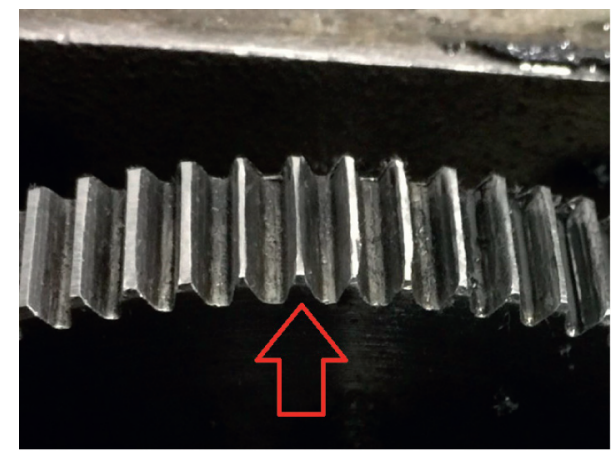

FIGURE 11: Tooth 36 after 800 hours of experiment.

crown, shows that only some points are generating discontinuity in the signal.

After 800 hours of experiments, one point with a greater magnitude is observed around tooth number 36 .

The exact position of the faulted tooth is measured thanks to a trigger that monitors the passage of tooth 1 .

When the experiment was interrupted and the reducer was opened to check the gear, significant wear was observed in tooth 36. Figure 11 shows the wear of this tooth in terms of thickness in comparison with the other teeth.

\section{Conclusions}

Morlet wavelet as a continuous wavelet transform for vibration analysis was an excellent technique for performing time-frequency signal analysis. When applied in a pair of gears, it indicated the presence of defects in the teeth.

The experiment represented the complete useful life of the gear, thus enabling vibration analysis and detection of bathtub curve characteristics. So, the novelty of this paper is the application of Morlet's continuous wavelet transform throughout the life of a gear, analysis of each period, and comparison with the bathtub curve.

At the end of the useful life of the gear, wavelet analysis indicated a tooth with a peak of magnitude that differed from that of the other teeth. The experiment was interrupted and the tooth was visually analyzed, revealing significant wear, in a much more advanced stage than the other teeth. The work showed that a continuous wavelet transform is a good tool for predictive gear maintenance. It is great for time-frequency signal analysis. And it was able to indicate the presence of defects in the teeth.

Moreover, the continuous wavelet transform was successfully used to filter the signals. Because the transform functions in the time-frequency domain, it is possible to create band-pass filters both in time and in frequency, thus enabling signal processing.

TSA is great for removing signal noise. The CWT is useful for analyzing the vibration signal in the time-frequency plane.

Among the possibilities of wavelet, Morlet is one of the most widely used in the literature for vibration analysis.

\section{Data Availability}

The data used to support the study can be available upon request to the corresponding author.

\section{Conflicts of Interest}

The authors declare that there are no conflicts of interest regarding the publication of this paper.

\section{Acknowledgments}

This study was partially funded by the Brazilian agency FAPESP (grant no. 2014/14360-1). The authors also thank CAPES and CNPq for continuous support.

\section{References}

[1] P. D. Mcfadden and M. M. Toozhy, "Application of synchronous averaging to vibration monitoring of rolling element bearings," Mechanical Systems and Signal Processing, vol. 14, no. 6, pp. 891-906, 2000.

[2] F. Bonnardot, M. El Badaoui, R. B. Randall, J. Danière, and F. Guillet, "Use of the acceleration signal of a gearbox in order 
to perform angular resampling (with limited speed fluctuation)," Mechanical Systems And Signal Processing, vol. 19, no. 4, pp. 766-785, 2005.

[3] P. D. Mcfadden, "Detecting fatigue cracks in gears by amplitude and phase demodulation of the meshing vibration," Journal of Vibration and Acoustics, vol. 108, no. 2, pp. 165-170, 1986.

[4] G. Dalpiaz, U. Meneghetti, and U. Meneghetti, "Monitoring fatigue cracks in gears," NDT \& E International, vol. 24, no. 6, pp. 303-306, 1991.

[5] D. C. Lin, M. F. Golnataghi, M. F. Golnaraghi, and F. Ismail, "The dimension of the gearbox signal," Journal of Sound and Vibration, vol. 208, no. 4, pp. 664-670, 1997.

[6] D. G. Da Silva, "Diagnóstico de falha em redutores de velocidade submetidos a variação de potência. 294 f," Faculty of Engineering, Paulista State University "Júlio de Mesquita Filho”, Ilha Solteira, Brazil, Master's degree, 2001.

[7] A. Green, "The study of the failure modes of a spur gear using vibration an particle analysis techniques," Melbornel: James Cook University, School of Engineering, Townsville, Australia, 2003.

[8] A. C. Gonçalves, A. T. Pashoalini, and M. Bazani, "Predictive maintenance of a worm reducer with an unbalanced load," International Journal of Surface Science and Engineering (Print), vol. 8, pp. 302-317, 2014.

[9] A. C. Gonçalves and L. R. Padovese, "Vibration and oil analysis for monitoring problems related to water contamination in rolling," in Proceedings of the 1st International Brazilian Conference on Tribology, TriboBR-2010 and 2nd International Tribology Symposium of IFToMM, ITS-IFToMM 2010, pp. 80-90, Rio de Janeiro, Brazil, November 2010.

[10] R. G. T. Almeida and L. R. Padovese, "Detection of oil viscosity variation in a gearbox by vibration analysis," in Brazilian Congress of Mechanical Engineering, CD-ROM, João Pessoa, Brazil, 2002.

[11] W. J. Wang, P. D. Mcfadden, and P. D. McFadden, "Application of orthogonal wavelets to early gear damage detection," Mechanical Systems And Signal Processing, vol. 9, no. 5, pp. 497-507, 1995.

[12] R. K. Mobley, An Introduction to Predictive Maintenance, Plant Engineering, Downers Grove, IL, USA, 2nd edition, 2002.

[13] H. Zeng, T. Lan, and Q. Chen, "Five and four-parameter lifetime distributions for bathtub-shaped failure rate using perks mortality equation," Reliability Engineering \& System Safety, vol. 152, pp. 307-315, 2016.

[14] W. J. Roesch, "Using a new bathtub curve to correlate quality and reliability," Microelectronics Reliability, vol. 52, no. 12, pp. 2864-2869, 2012.

[15] A. Arato, Manutenção preditiva usando análise de vibrações, Research Gate, Boston, MA, USA, 2004.

[16] E. F. M. S. Silva, "Investigação de técnicas para o acompanhamento do desgaste de um par engrenado utilizando tribologia. 136 f," Faculty of Engineering, Paulista State University Júlio de Mesquita Filho, Ilha Solteira, Brazil, Master's degree, 2015. 